\title{
Pavlovian determiners of behavioral momentum
}

\author{
JOHN A. NEVIN \\ University of New Hampshire, Durham, New Hampshire
}

\begin{abstract}
Pigeons pecked keys on a six-component multiple schedule of food reinforcement arranged in successive pairs on three keys. On all three keys, the schedule in the first component was variableinterval $120 \mathrm{sec}$. On one key, the second component was variable-time $24 \mathrm{sec}$; on another, it was variable-time $120 \mathrm{sec}$; and on the third, extinction. Pairs of components were separated by timeout. In this arrangement, second-component stimuli were differentially correlated with food in their presence, and first-component stimuli were differentially correlated with second-component food in serial fashion. After baseline performance stabilized, resistance to change was assessed by prefeeding, by discontinuing food, and by presenting free food at random times throughout sessions. There was no consistent relation between baseline response rates in the first component and reinforcement rate in the second component. When assessed by prefeeding or extinction, resistance to change in the first component was positively related to reinforcement rate in the second component, demonstrating that serial stimulus-reinforcer contingencies affected resistance to change.
\end{abstract}

Two aspects of free-operant performance may be distinguished: (1) the rate of responding under maintained conditions of reinforcement, and (2) the persistence of that response rate when some aspect of those conditions is changed. Nevin, Mandell, and Atak (1983) suggested that this distinction is formally analogous to that between velocity and mass in determining the momentum of a physical body, according to Newtonian mechanics. Responding continues at a steady rate under constant conditions until acted upon by a new variable, just as a body persists in motion until acted upon by an external force. Moreover, the change in response rate effected by a given variable depends on the rate of reinforcement, just as the change in motion of a body depends on its mass. Nevin et al. (1983) explored some quantitative aspects of the Newtonian metaphor, identifying response rate with velocity and resistance to change with mass. This paper, in a more qualitative vein, is concerned with the contribution of Pavlovian stimulus-reinforcer contingencies to behavioral mass.

Two recent studies, both employing multiple schedules with pigeons as subjects, will serve to illustrate the distinction between response rate and resistance to change, and to suggest the potential role of Pavlovian contingencies. Fath, Fields, Malott, and Grossen (1983) lighted the pecking key red or green alternately for 1-min periods, separated by 30 -sec dark-key periods. Food reinforcers were available at variable intervals averaging $1 \mathrm{~min}$ (VI $1 \mathrm{~min}$ ) in both red and green components. When the key was red, food was given only for pecks spaced about $3 \mathrm{sec}$

This research was supported in part by NSF Grant BNS 79-24082. I am indebted to the students in my laboratory for help in conducting the study.

The author's mailing address is Department of Psychology, University of New Hampshire, Durham, NH 03824. apart, resulting in low pecking rates. When the key was green, food was given only for pecks spaced about $1 \mathrm{sec}$ apart, resulting in higher pecking rates. Thus, response rates differed but reinforcement rates, and thus stimulusreinforcer contingencies, were the same in the two schedule components. When response-independent food was presented during dark-key periods, response rates decreased by about the same proportion in both components, demonstrating equal resistance to change.

Using component lengths and dark-key periods exactly like Fath et al. (1983), Nevin et al. (1983) arranged conventional VI schedules that provided different average rates of reinforcement (e.g., VI $28 \mathrm{sec}$ when the key was red, and VI $86 \mathrm{sec}$ when the key was green). Thus, keypecking was reinforced three times more often when the key was red than when it was green, but it is also true that red was better correlated with food than was green. For example, onset of red was three times more likely to be followed by food within, say, 10 sec than was onset of green. At a more molar level, red was correlated with an increase in food rate, relative to the overall session average, whereas green was correlated with a decrease. Under these conditions, there was no systematic difference in maintained response rates in the two components, but the introduction of response-independent food during dark-key periods yielded consistently smaller decreases in the component with the greater rate of reinforcement. This difference in resistance to change may have resulted from differential stimulus-reinforcer contingencies, quite apart from (or in addition to) the difference in frequency of reinforcement for the keypeck.

Isolation of Pavlovian stimulus-reinforcer relations requires that operant response-reinforcer relations remain constant across components, whereas stimulus-reinforcer relations vary. One method for doing this is to present response-independent food reinforcers on variable-time 
(VT) schedules at different rates in two or more schedule components and then examine the resistance to change of the autoshaped keypecking induced by the component stimuli. Several attempts at this sort of analysis in my laboratory have failed because of extreme variability in induced keypecking within and between subjects. Moreover, when stable responding is maintained, adventitious reinforcement of pecking may contribute to resistance to change.

A more generally applicable method is described in Figure 1. After a 2-min time-out, one of three keys was chosen from a quasi-random sequence and lighted for $1 \mathrm{~min}$, defining the first component (C1). A different color was then presented for $1 \mathrm{~min}$, defining the second component (C2). During C1, a VI 120-sec schedule was in effect regardless of which key was lighted. Thus, operant contingencies were identical across keys, and the VI schedule insured that reasonably stable rates of keypecking would be maintained. During C2, food was presented independently of responding at rates that varied across keys: VT $24 \sec (150 / h)$; VT $120 \sec (30 / h)$, and extinction $(0 / h)$. Thus, with respect to $C 1$, serial Pavlovian contingencies differed across keys because (1) the $\mathrm{C} 2$ schedule is perfectly correlated with key location and color in $\mathrm{C} 1$, and (2) the transition from $\mathrm{Cl}$ to $\mathrm{C} 2$ is responseindependent and unrelated to performance in $\mathrm{C} 1$ at any time.

In terms of the conventional Pavlovian paradigm, one could view the $\mathrm{C} 1$ stimuli and schedules as the CSs and the C2 stimuli and schedules as the USs in a differential conditioning experiment. If the resistance to change of the operant performances in $\mathrm{C} 1$ depends on these CS-US arrangements, one can conclude that Pavlovian, stimulusreinforcer contingencies affect "behavioral mass" in the Newtonian metaphor.

The response rate maintained in $\mathrm{C} 1$ may also be related to the C2 schedule that follows it. Williams $(1979,1981)$ has shown that response rate in a schedule component is negatively related to the rate of reinforcement in the fol-

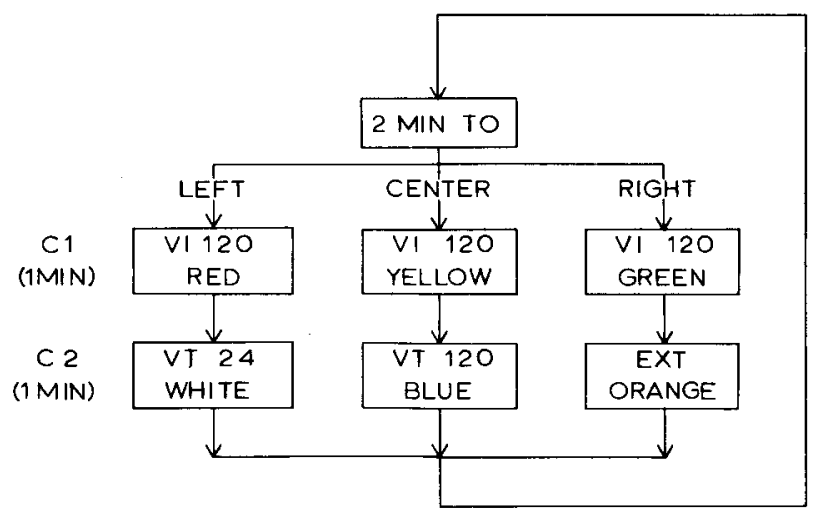

Figure 1. Diagram of procedure for the study of serial Pavlovian stimulus-reinforcer contingencies. lowing component. If resistance to change in a schedule component is positively related to the rate of reinforcement in the following component, as a Pavlovian analysis suggests, the distinction between response rate and resistance to change is further strengthened.

\section{METHOD}

Subjects

Three male White Carneaux pigeons were maintained at $80 \%$ of their free-feeding weights. All three birds had been exposed to autoshaping procedures in a separate experiment.

\section{Apparatus}

The experiment was conducted in a three-key Lehigh Valley pigeon chamber equipped with houselight and grain feeder. Each key could be transilluminated with various colored lights. A blower provided ventilation and masking noise. Electromechanical equipment in an adjacent room arranged experimental events and recorded data.

\section{Procedure}

Since all subjects had been trained to peck lighted keys, they were exposed to the procedure described in Figure 1 without special training. Sessions were conducted 5 to 7 days per week. Sessions always began with a 2-min time-out, with houselight on, and consisted of 27 C1-C2 cycles, 9 on each key. Reinforcer duration was $5 \mathrm{sec}$ for the first 120 sessions, and was then reduced to $3.5 \mathrm{sec}$ to avoid progressive weight increases.

After 80 sessions of baseline training, resistance to change was assessed by prefeeding various amounts of grain to each subject, $13 / 4 \mathrm{~h}$ before selected sessions. The amounts were $10 \%, 15 \%$, or $20 \%$ of the birds' free-feeding weights, with each value presented three times in an irregular order. Prefeeding was given only if the birds had recovered their $80 \%$ weight levels and at least three sessions of baseline training with stable performance had been conducted since the previous prefeeding session.

After completion of these 9 prefeeding sessions, the birds were given an additional 40 sessions of baseline training, now with a $3.5-\mathrm{sec}$ reinforcer duration. Then resistance to change was assessed by withholding food for five consecutive sessions of extinction.

Following extinction, baseline performance was reestablished and maintained for 12 additional sessions. A third assessment of resistance to change was then performed. Throughout the entire duration of a session, the grain feeder was operated for $2 \mathrm{sec}$ at random times determined by pulsing a probability gate every $3 \mathrm{sec}$. The probability of operating the grain magazine was either .05 or .20 , resulting in approximately 108 or 4322 -sec food presentations per session. Each value was employed three times, in ABBAAB order, on six successive Fridays.

Throughout this first phase of the experiment, the C2 schedule on the left key was VT $24 \mathrm{sec}$, and that on the right was EXT. To control for key color or position effects, the $\mathrm{C} 2$ schedules on the left and right were reversed in the second phase. After 80 baseline sessions, resistance to change was assessed by the presentation of response-independent food for $2 \mathrm{sec}$ at random times throughout the session. Three such sessions were conducted, once per week, with the probability of food presentation set at .10 every $3 \mathrm{sec}$. Following another 50 baseline sessions, resistance to change was assessed by prefeeding three different amounts of grain, three times each in irregular order, before sessions selected as above. For Birds $\mathrm{B} 15$ and $\mathrm{B} 17$, the amounts were $5 \%, 10 \%$, and $15 \%$ of their ad-lib weights; for Bird 61 , the amounts were $5 \%, 71 / 2 \%$, and $10 \%$ of its ad-lib weight. After completion of this prefeeding series, 12 more baseline sessions were conducted, and then food was witheld for five consecutive sessions of extinction. 
During the third and last phase of the experiment, a final series of determinations was conducted to ascertain whether initial performance could be recaptured. The $\mathrm{C} 2$ schedules on the left and right keys were again reversed to VT $24 \mathrm{sec}$ and EXT, respectively. After 100 baseline sessions, resistance to change was assessed by presenting response-independent food for three sessions, once per week, as in the second phase. After five more baseline sessions, a series of nine prefeeding sessions was conducted, with Bird B17 receiving $10 \%, 15 \%$, or $20 \%$ and Bird 61 receiving $5 \%, 10 \%$, and $15 \%$ of their ad-lib weights three times each in irregular order. (Bird B15 died midway through this prefeeding series.) Finally, after 12 more baseline sessions, the experiment ended with five consecutive sessions of extinction.

\section{RESULTS}

Baseline response rates in all three phases are summarized in Figure 2. The filled circles and squares represent averaged response rates for the 10 sessions preceding the first assessment of resistance to change in each phase. The patterns of performance vary widely across birds and phases. Across keys in C2, Bird B15 always responded most on the key with 150 reinforcers per hour (VT $24 \mathrm{sec}$ ) and least on the key with 0 reinforcers per hour (EXT), but B17 did so only in Phases 1 and 3. Bird 61 always responded most on the center key, with 30 reinforcers per hour (VT $120 \mathrm{sec}$ ).

All subjects exhibited substantial rates of keypecking in C1 (VI $120 \mathrm{sec}$ on all keys in all phases), but again the patterns varied across birds and phases. Each bird exhibited its highest $\mathrm{Cl}$ response rate on the key that had extinction in $\mathrm{C} 2$ in two of the three phases, with two birds exhibiting this effect in each phase. These data give only weak evidence of contrast effects based on the following schedule.

In order to assess the possibility that the expected following-schedule contrast effect was confounded with biases based on key color and location, or shifting baseline levels of responding, response rates on the left and right keys were expressed as ratios of the response rate on the center key for each phase of the experiment. Relative to the center key, responding on the left should increase from Phase 1 to Phase 2 and then decrease from Phase 2 to Phase 3, whereas responding on the right should follow the opposite pattern if response rates in $\mathrm{C} 1$ are negatively related to reinforcement rate in $\mathrm{C} 2$. Figure 3 shows that this result was obtained for B17 on the left only and for B15 on the right only. Thus, the expectation that response rate in $\mathrm{Cl}$ would be negatively related to reinforcement rate in the following $\mathrm{C} 2$ (Williams, 1979, 1981) was not confirmed.

The unfilled circles in Figure 2 represent averaged $\mathrm{C} 1$ response rates for the sessions preceding each test for resistance to change: 6 (or 3 in Phases 2 and 3) preceding the response-independent food sessions, 9 preceding the prefeeding sessions, and 3 consecutive sessions preceding extinction. The averages for these sessions, which were distributed over some 80 to 150 sessions within each phase, do not differ markedly from those for

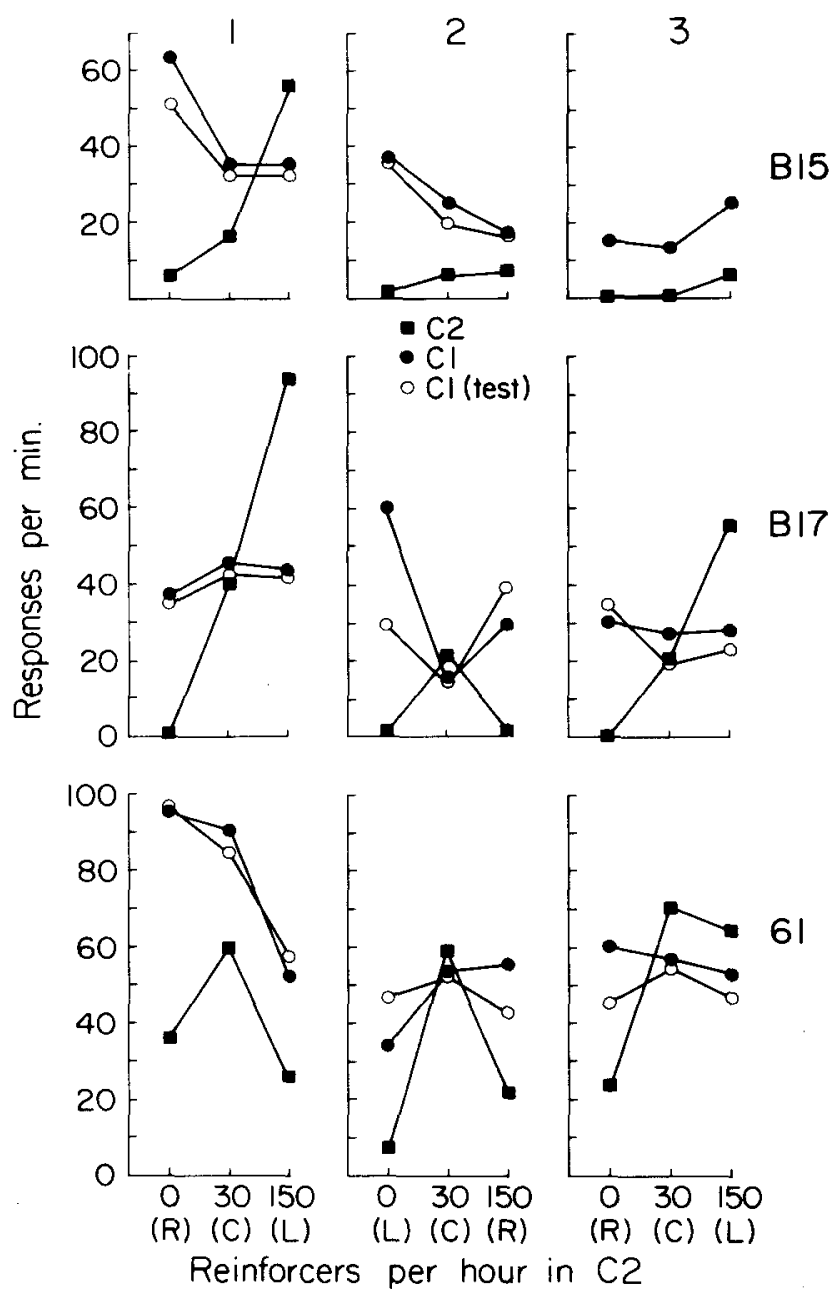

Figure 2. Rates of responding in C2 (filled squares) and C1 (filled circles) during the last $\mathbf{1 0}$ sessions of baseline training, as a function of the rate of response-independent reinforcement arranged in C2 during the three phases of the experiment. The unfilled circles show average response rates in $\mathrm{C1}$ during sessions immediately preceding tests for resistance to change.

the 10 consecutive baseline sessions that preceded the first resistance-to-change test in each phase. No data are presented for $\mathrm{C} 2$ during testing because the remainder of this report will concentrate on resistance to change in $\mathrm{C} 1$.

Resistance to prefeeding, expressed as average proportions of response rates in each preceding baseline session, is shown in Figure 4. If resistance to change in $\mathrm{Cl}$ is positively related to rate of food presentation in $\mathrm{C} 2$, the filled circles (left key, VT $24 \mathrm{sec}$ in C2) should lie above the filled triangles (right key, EXT in C2), with the filled squares (VT $120 \mathrm{sec}$ in C2) in between, in Phases 1 and 3. This order should be reversed in Phase 2. Phase 1 data follow this pattern for B15 and B17. Bird 61 gave usable data in only three of the nine prefeeding sessions, but no responding during the remaining six. Its data are, therefore, less reliable, but at least accord with those of the 


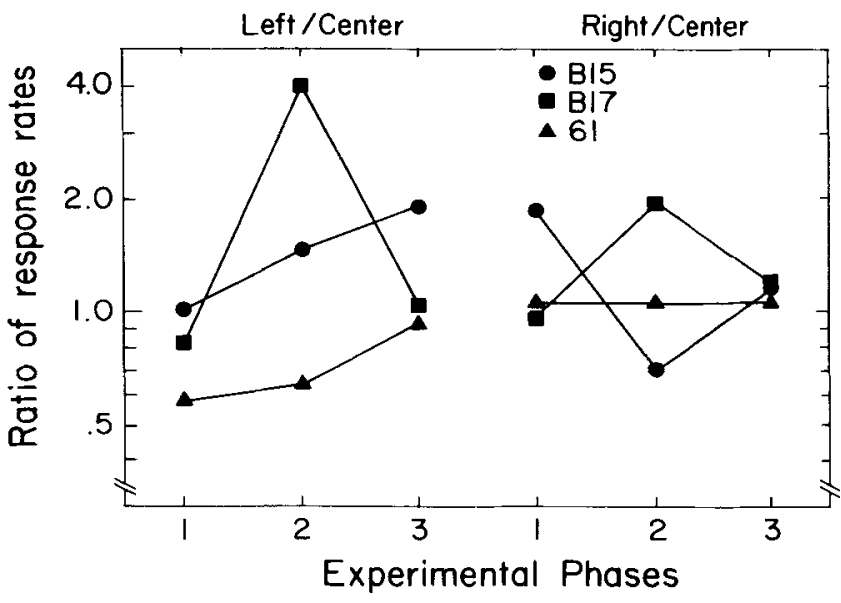

Figure 3. Ratios of response rates in $\mathrm{Cl}$ on the left key to the rates on the center key, and those on the right key to those on the center key, over the three phases of the experiment.

other birds in the ordering of circles and triangles. In Phase 2, the order of data points is maintained, with reduced separation, for $B 15$, whereas the separation of functions is eliminated for $B 17$, to be restored in Phase 3, replicating Phase 1 . For Bird 61, the filled triangles lie above the circles in Phase 2 and are either below or indistinguishable from the circles in Phase 3 . Thus, in C1, resistance to prefeeding was positively related to the rate of food presentation in $\mathrm{C} 2$ in a majority of instances, and changed in the appropriate direction with key reversals in all cases.

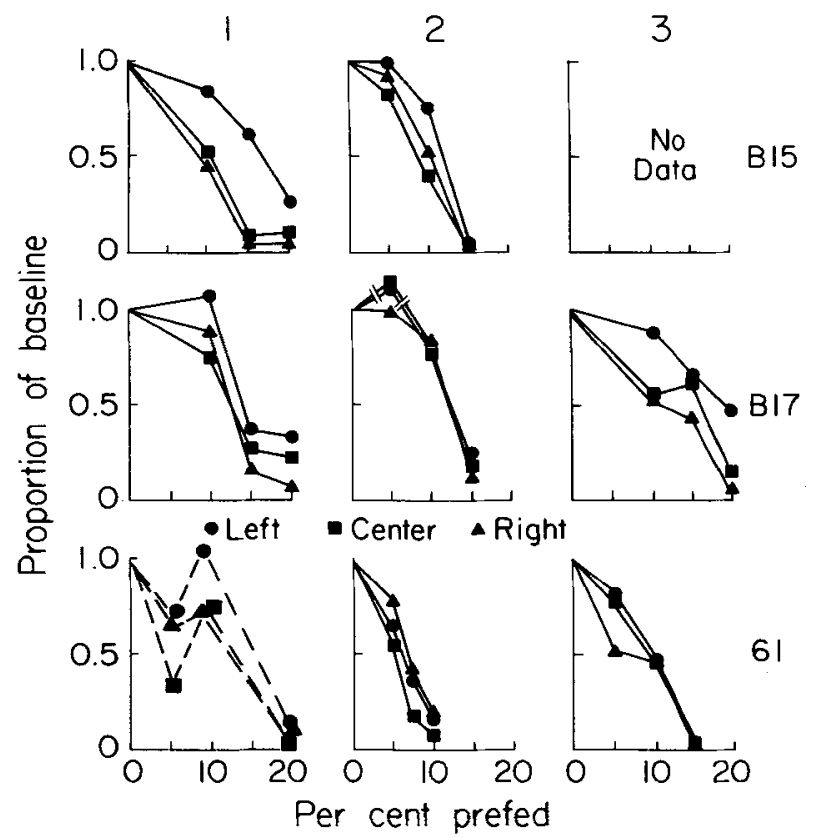

Figure 4. Average proportions of baseline response rates in $\mathrm{C} 1$ during sessions when the birds were prefed various amounts of grain, over the three phases of the experiment. B15 died during Phase 3 determinations. Bird 61 responded in only three sessions during Phase 1 determinations.
Resistance to extinction is shown as proportion of response rate in the three preceding baseline sessions in Figure 5, following the format of Figure 4. The circles lie above the triangles in Phase 1 for $\mathrm{B} 15$ and B61, and in Phase 3 for B17 and B61. The triangles generally lie above the circles for B17 and B61 in Phase 2. Reversals from Phase 1 to Phase 2 and from Phase 2 to Phase 3 lead to appropriate changes of ordering or separation of functions.

The reliability of these effects is better shown in Figure 6, where proportion of baseline on the left key is plotted against proportion of baseline on the right key for all three phases of the experiment. Filled points come from Phases 1 and 3; unfilled points come from Phase 2. Points lying above the major diagonal indicate greater resistance to change on the left key. With a few exceptions for B17, the filled points lie above the diagonal and the unfilled points are either below or closer to the diagonal. Thus, resistance to change was relatively greater in $\mathrm{C} 1$ on the left key than on the right key when left signaled VT 24sec in $\mathrm{C} 2$ in Phases 1 and 3, and this difference was reduced or reversed in Phase 2 when the left signaled EXT in $\mathrm{C} 2$.

The effects of random food presentations did not vary consistently with schedule and key position for any of the three subjects. Accordingly, only summary data are presented for this procedure.

A convenient quantitative summary of resistance to change is the average weighted proportion of baseline, $\overline{\mathbf{p}}$ (see Nevin, Mandell, \& Yarensky, 1981). To compute $\overline{\mathrm{p}}$, the values of proportion of baseline were multiplied by the values of the assessment variable producing them (percent prefed, session number in extinction, or probability of random food presentation). These products were then summed and divided by the sum of the values of the assessment variable. The resulting $\bar{p}$ values were then averaged across phases to show how $\overline{\mathrm{p}}$ depended on the rate of food presentation in $\mathrm{C} 2$. Whenever complete data were available for a given assessment operation in both Phases 1 and 3 , these $\bar{p}$ values were first combined and then averaged with those for Phase 2 so as to avoid giving undue weight to the first phase and its replication.

The results are displayed in Figure 7. For the prefeeding and extinction assessments, $\overline{\mathrm{p}}$ in $\mathrm{C} 1$ was higher when the $\mathrm{C} 2$ schedule presented food 150 times per hour than when the $\mathrm{C} 2$ schedule was extinction, for all subjects. This summary is, of course, consistent with the more detailed data of Figure 6. On the center key, which remained constant at $\mathbf{3 0}$ food presentations per hour in $\mathrm{C} 2$ throughout the experiment, $\bar{p}$ was intermediate in three of six cases. Thus, there is a rough positive relation between $\bar{p}$ in $\mathrm{Cl}$ and rate of food presentation in $\mathrm{C} 2$, at least for prefeeding and extinction. The data for random food assessments show no consistent differences in relation to the $\mathrm{C} 2$ schedule.

The relation between resistance to prefeeding or extinction and rate of reinforcement in C2 cannot reasonably be ascribed to adventitious reinforcement of responding during $\mathrm{C} 1$ by onset of $\mathrm{C} 2$. Such adventitious reinforce- 


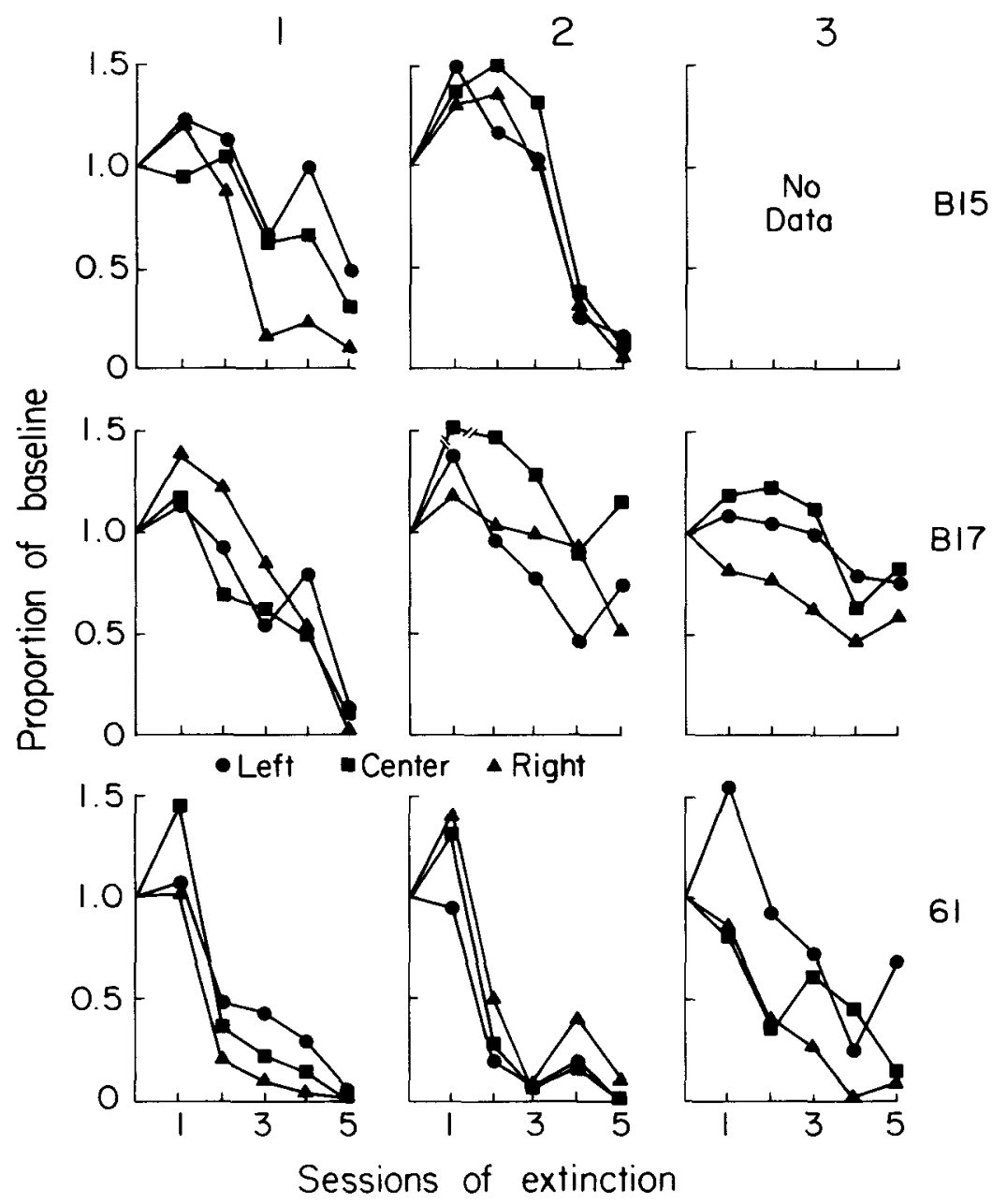

Figure 5. Average proportions of baseline response rates in $\mathrm{C} 1$ during five consecutive sessions of extinction, over the three phases of the experiment.

ment would be most likely when response rate in $\mathrm{C} 1$ was high. However, consideration of Figures 2, 4, and 5 suggests that the clearest examples of enhanced resistance to change in $\mathrm{C} 1$ when $\mathrm{C} 2$ has a high rate of reinforcement (e.g., B17, prefeeding, Phase 3) do not correspond to conditions in which $\mathrm{C} 1$ response rate was particularly high. Thus, it seems safe to attribute differential resistance to prefeeding or extinction to the differential Pavlovian contingencies between $\mathrm{C} 1$ stimuli and food reinforcement in $\mathrm{C} 2$.

\section{DISCUSSION}

The term "learning" may be used to designate changes in behavior that result from exposure to some training procedure and that are relatively persistent when that procedure is discontinued. One would speak of behavior with a low pretraining baseline as "well learned" if it occurred frequently and reliably during the final stages of training and persisted with little disruption when training ended. Conversely, one would be unlikely to speak of learning if the training procedure did not increase some aspect of behavior or if behavior returned to its pretraining baseline immediately upon cessation of training.

The concept of behavioral momentum captures what we seem to mean by "learning" fairly well, because it entails both a velocity component (response rate) and a mass component (resistance to change). The process of reinforcement increases both from pretraining levels. In general, asymptotic response rates under constant training conditions and resistance to change when those conditions are altered are both positively related to the rate of reinforcement. Thus, their combination-what we generally mean by "learning"-is a positive function of reinforcement frequency, just as various learning theorists have said for half a century.

Although both response rate and resistance to change are affected by reinforcement, their determiners can be separated, as in the studies by Fath et al. (1983) and Nevin et al. (1983), described above. These studies suggested that response rate depended on contingencies between responses and reinforcers, whereas resistance to change 

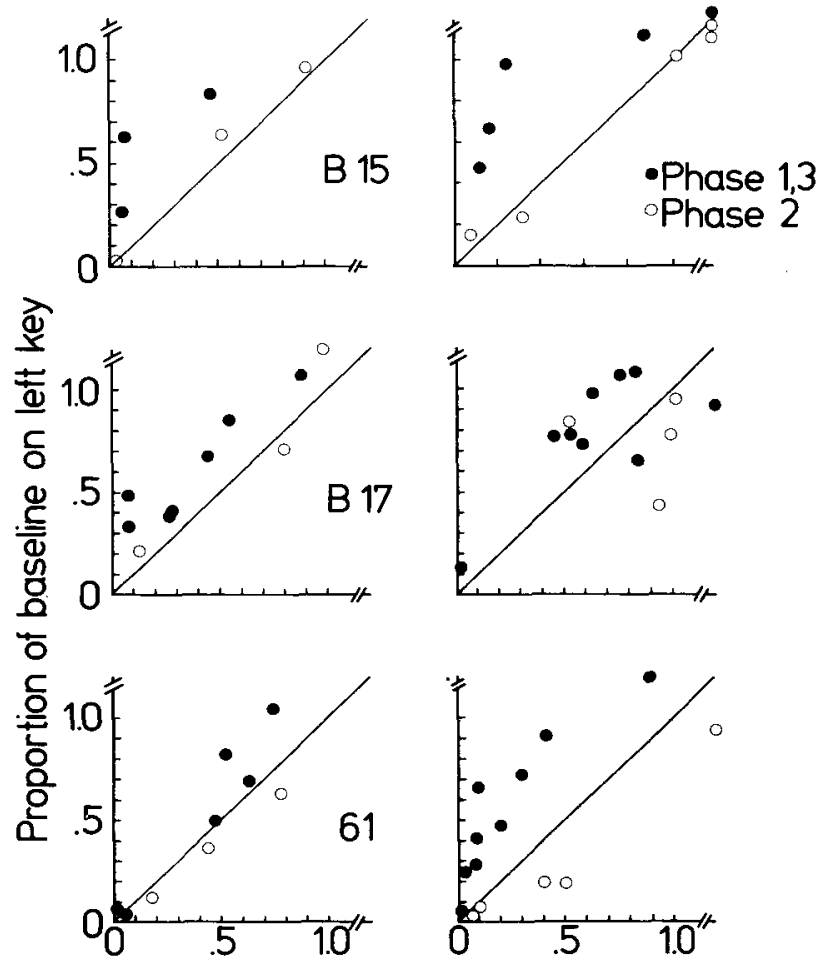

Proportion of baseline on right key

Figure 6. Proportion of baseline on the left key in relation to proportion of baseline on the right key during prefeeding (left column) and extinction (right column). The data points are taken from Figures $\mathbf{4}$ and 5 , where they appear as filled circles and filled triangles. In this figure, filled circles come from Phases 1 and 3 , during which the left key had 150 reinforcers per hour in $\mathrm{C} 2$ and the right key had extinction in C2. The unfilled circles come from Phase 2, during which the left key had extinction and the right key had 150 reinforcers per hour in C2. Differential control over resistance to change in $\mathrm{C} 1$ by the schedule in $\mathrm{C2}$ is demonstrated by the relative locations of the filled and unfilled circles. depended on overall rate of reinforcement. The present experiment suggests that a critical aspect of the relation between resistance to change and rate of reinforcement is Pavlovian: the correlation between stimuli and rate of reinforcement, with response-reinforcement contingencies held constant. It is therefore tempting to suggest that the velocity component of behavioral momentum is determined by operant, response-reinforcer contingencies, whereas the mass component is determined by Pavlovian, stimulus-reinforcer contingencies. There are, however, a few counterinstances. Differential reinforcement of high or low rates of responding, with reinforcement rate controlled, may sometimes affect resistance to change as well as response rate (e.g. Blackman, 1968; Nevin, 1974, Experiment 4). Conversely, stimulus-reinforcer contingencies may affect response rate (e.g., Gamzu \& Williams, 1973; see Schwartz \& Gamzu, 1977, for review) as well as resistance to change. Thus, it may be that both velocity and mass are determined by both operant and Pavlovian factors in some situations.

When two stimuli signaling different schedules are presented in sequence, operant and Pavlovian factors may work in opposition. The following-schedule contrast effect reported by Williams $(1979,1981)$ may be interpreted in terms of operant contingencies if it is assumed that the controlling variable is the relative rate of reinforcement, and that the following component receives extra weight in the estimation of relative reinforcement (cf. Williams, 1983). A forward-looking mechanism of this sort can also be interpreted in Pavlovian terms, on the basis of experienced sequences of stimuli and food reinforcement. However, the Pavlovian relations work in opposition to relative reinforcement. For example, a stimulus correlated with a high rate of reinforcement relative to that in the following stimulus is also, presumably, a Pavlovian inhibitor, because it predicts an impending decrease in rein-

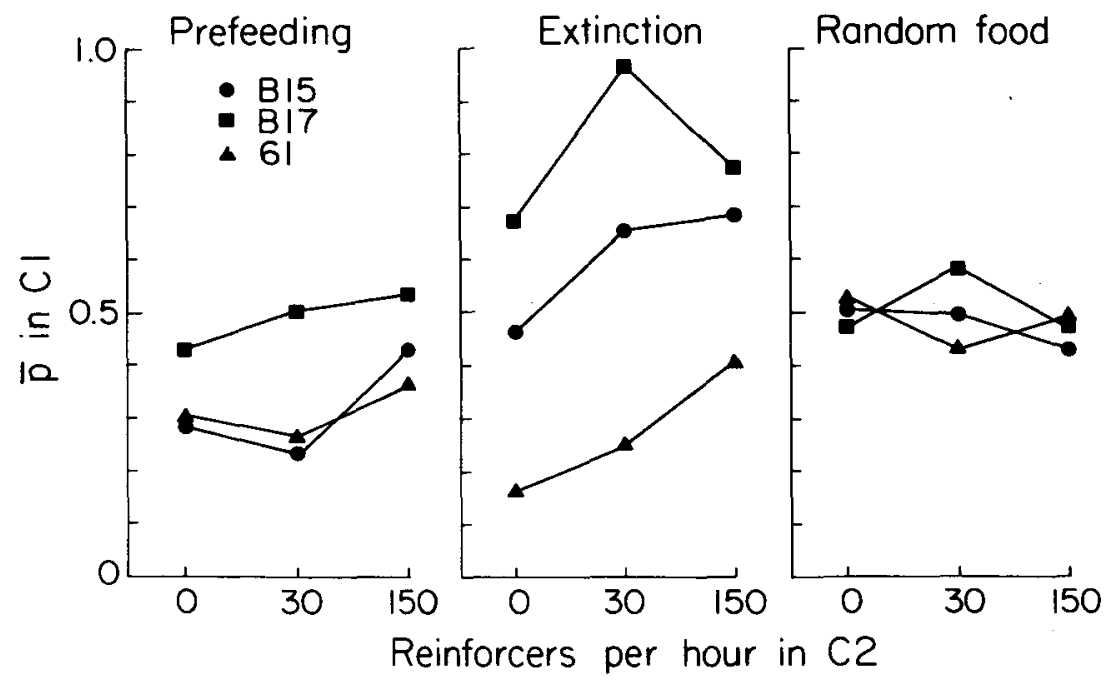

Figure 7. A summary statistic (p) characterizing resistance to change in $\mathrm{C1}$ as a function of the rate of response-independent reinforcement in $\mathrm{C2}$, for three separate assessment methods. 
forcement rate. In Williams's work, these conditions produce an increase in response rate, and in this study they produce a reduction in resistance to change, consistent with the velocity-as-operant and mass-as-Pavlovian dichotomy offered above.

With respect to the present experiment, however, confidence in this separation must be limited, because the Williams-type contrast effect was not replicated, and because the effects on resistance to change were not large. There is no clear reason for the failure to replicate the following-schedule contrast effect: The present schedule values and component durations were within the range employed in Williams's work, so one is left with the unsatisfying conclusion that some other factors are critical for following-schedule contrast. The reason for the small effects on resistance to change is somewhat clearer, though. The serial differential Pavlovian contingencies between $\mathrm{C} 1$ stimuli and $\mathrm{C} 2$ reinforcement rate were superimposed on identical operant and Pavlovian contingencies during $\mathrm{Cl}$. That is, both the immediate stimulus-reinforcer relations (transition from time-out to a signal correlated with food every $2 \mathrm{~min}$, on average) and responsereinforcer relations (one peck reinforced every $2 \mathrm{~min}$, on average) were the same on all three keys in $\mathrm{Cl}$, and might well weaken the differential effects of the serial Pavlovian contingencies between $\mathrm{C} 1$ and $\mathrm{C} 2$. The effect is, however, replicable. Nevin (1984b) repeated the present extinction results in many fewer training sessions with $\mathrm{C} 1$ shorter and variable in duration, with different values for the VI schedules, and a shorter time-out.

Consideration of the Pavlovian nature of the relationship controlling these small effects may help us to understand why random food presentations did not give effects consistent with those for prefeeding and extinction. By the very nature of the procedure, random food presentations must disrupt the differential contingencies between the various component stimuli and food, and could easily abolish weak differential effects.

The positive relation between resistance to prefeeding in $\mathrm{C} 1$ and rate of food presentation in $\mathrm{C} 2$ parallels some results for chained schedules. In a chained schedule, responding during an initial link intermittently produces the terminal link, in which further responding produces food. Thus, chained schedules include serial stimulusreinforcer contingencies of the sort arranged in the present study. Nevin et al. (1981) found that resistance to prefeeding in the initial link (analogous to $\mathrm{Cl}$ ) was an increasing function of food access per unit time in the terminal link (analogous to $\mathrm{C} 2$ ). Thus, the relation holds across different paradigms.

Chained schedules also involve response-reinforcer contingencies in that the onset of the terminal link is contingent upon the response in the initial link. Nevin (1984b) compared a condition in which the transition from $\mathrm{C} 1$ to $\mathrm{C} 2$ was contingent upon a keypeck at the end of $\mathrm{C} 1$ with a condition in which the transition from $\mathrm{C} 1$ to $\mathrm{C} 2$ was response-independent, as here. He found that this con- tingency did not increase resistance to extinction, although it did increase response rate relative to the responseindependent condition. The absence of an effect on resistance to change of this explicit operant contingency in Nevin's (1984b) experiment gives further evidence against the possible role of adventitious reinforcement of pecking in $\mathrm{C} 1$ by $\mathrm{C} 2$ onset in the present study, and strengthens the suggestion that behavioral mass depends on Pavlovian stimulus-reinforcer contingencies.

The entire discussion of behavioral momentum, and especially behavioral mass, may strike some readers as decidedly Hullian in tone. Behavioral mass might easily be construed as analogous to habit strength $\left(\mathrm{sH}_{\mathrm{R}}\right)$, which must be multiplied by terms such as drive (D) or incentive $(\mathrm{K})$-which presumably would contribute to velocity--before emerging into the world of measurable performance. However, it would be an error to regard the present approach as a reincarnation of the Hullian program. Behavioral mass is simply the name of a higher order dependent variable (cf. Nevin, 1984a), summarizing the function relating proportion of baseline to whatever independent variable is employed to assess resistance to change. The weighted proportion of baseline used as the dependent variable in Figure 7 is one way to characterize behavioral mass; Nevin et al. (1983) have provided another, with the properties of a ratio scale. The present approach does not hypothesize properties for behavioral mass and then derive predictions, as in Hull's (1943) theorizing. Instead, the approach is to examine data on response rate and resistance to change, isolate invariances and orderly differences, and summarize those aspects of the data with terms that suggest an analogy between the motion of a physical body and the actions of a living organism. The analogy will be useful to the extent that it aids in the analysis of behavioral processes involved in what we generally mean by learning.

\section{REFERENCES}

Blackman, D. E. (1968). Response rate, reinforcement frequency, and conditioned suppression. Journal of the Experimental Analysis of Behavior, 11, 503-516.

Fath, S. J., Fields, L., Malott, M. K., \& Grossen, D. (1983). Response rate, latency, and resistance to change. Journal of the Experimental Analysis of Behavior, 39, 267-274.

Gamzu, E. R., \& Williams, D. R. (1973). Associative factors underlying the pigeon's key pecking in auto-shaping procedures. Journal of the Experimental Analysis of Behavior, 19, 225-232.

Hule, C. L. (1943). Principles of behavior. New York: AppletonCentury-Crofts.

NeVIN, J. A. (1974). Response strength in multiple schedules. Journal of the Experimental Analysis of Behavior, 21, 389-408.

Nevin, J. A. (1984a). Quantitative analyses. Journal of the Experimental Analysis of Behavior, 42, 421-434.

NEVIN, J. A. (1984b). Reinforcement, punishment, and resistance to change. Invited address, Association for Behavior Analysis, Nashville, TN.

Nevin, J. A. Mandell, C., \& Atak, J. R. (1983). The analysis of behavioral momentum. Journal of the Experimental Analysis of Behavior, 39, 49-59. 
Nevin, J. A., Mandell, C., \& Yarensky, P. (1981). Response rate and resistance to change in chained schedules. Journal of Experimental Psychology: Animal Behavior Processes, 7, 278-294.

Schwartz, B., \& Gamzu, E. (1977). Pavlovian control of operant behavior. In W. K. Honig \& J. E. R. Staddon (Eds.), Handbook of operant behavior. Englewood Cliffs, NJ: Prentice-Hall.

Williams, B. A. (1979). Contrast, component duration, and the following schedule of reinforcement. Journal of Experimental Psychology: Animal Behavior Processes, 5, 379-396.
Williams, B. A. (1981). The following schedule of reinforcement as a fundamental determinant of steady state contrast in multiple schedules. Journal of the Experimental Analysis of Behavior, 35, 293-310.

Williams, B. A. (1983). Another look at contrast in multiple schedules. Journal of the Experimental Analysis of Behavior, 39, 345-384

(Manuscript received November 1, 1983;

revision accepted for publication September 26, 1984.) 